\title{
Análise quantitativa e qualitativa dos riscos de uma refinaria de petróleo
}

Krisllen Samara Feitosa de Souza krisllen_samara@hotmail.com Universidade Federal de Campina Grande (UFCG), Monteiro, PB, Brasil

Augusto José da Silva Rodrigues augustojsrodrigues@gmail.com Universidade Federal de Campina Grande (UFCG), Tuparetama, PE, Brasil

\section{Mônica Ferreira de Brito Rocha}

monica.rocha.2013@gmail.com Universidade Federal de Campina Grande (UFCG), São José do Egito, PE, Brasil

Rylla Ohana da Silva Sales rylla_ohana@hotmail.com

Universidade Federal de Campina Grande (UFCG), Arcoverde, PE, Brasil

\section{Daniel Oliveira de Farias} daniel.farias@ufcg.edu.br Universidade Federal de Campina Grande (UFCG), Sumé, PB, Brasil

\author{
RESUMO
}

O crescente desenvolvimento tecnológico dos processos industriais impactou diretamente a ocorrência de eventos indesejáveis como acidentes de trabalho e ambientais, que por sua vez são partes vitais no que compete ao gerenciamento de informações voltadas para a área de finanças e investimento em seguros. Nesse cenário, buscou-se uma maior dedicação por parte dos governantes, empresários, da sociedade e comunidade técnicacientífica no entendimento de como eliminar de vez estes riscos quando possível ou amenizá-los em casos mais complexos. Dessa forma, o presente trabalho possuiu o objetivo de identificar e quantificar os possíveis efeitos físicos dos danos, em função de vazamentos acidentais, decorrentes da operação de um processo de Refino de Petróleo. Para obtenção de resultados com uma mínima margem de erro e um controle minucioso, buscou-se a utilização do software Aloha, que permite a visualização dos riscos inerente a atividades específicas a ambientes químicos de trabalho. Desta forma, fez-se necessário uma pesquisa bibliográfica aliada a conhecimentos adquiridos em sala de aula para alcançar tal realização. O trabalho permitiu identificar as estimativas e os níveis das zonas de ameaças dos perigos existentes, sendo possível quantificar os possíveis efeitos físicos dos danos na refinaria em estudo.
\end{abstract}

PALAVRAS-CHAVE: Acidentes de trabalho. Análise de riscos. Refinaria. 


\section{INTRODUÇÃO}

Acidente de trabalho é um evento crítico que pode ocorrer de forma inesperada e inusitada dentro de um ambiente trabalhista. Tal evento pode ser oriundo de diversos tipos de riscos que a atividade em questão oferece. Diante das consequências catastróficas que um acidente pode ocasionar, tanto para o trabalhador quanto para as organizações, tem-se abordado e investido com uma melhor prioridade na segurança do trabalho.

Risco sempre foi uma parte vital no gerenciamento da informação na área financeira de investimentos e de seguros. No entanto, o desenvolvimento tecnológico dos processos industriais trouxe consigo eventos indesejáveis do ponto de vista de acidentes expandidos em unidades industriais, que resultaram ao longo dos anos em perdas de vidas humanas e de grandes impactos ao meio ambiente. Esse cenário levou a sociedade civil, governos, empresários e a comunidade técnica e científica a dedicar uma maior atenção ao entendimento da sequência lógica desses eventos com o objetivo de projetar, construir e operar unidades industriais que ofereçam riscos conhecidos e aceitos pelas partes interessadas do empreendimento.

Em prol da obtenção de conhecimento e controle as corporações vêm investindo cada vez mais em estudos, programas e softwares que permitem a visualização dos riscos inerentes ao tipo de atividade e ao ambiente de trabalho. Logo, este trabalho teve como principal objetivo, identificar e quantificar os possíveis efeitos físicos dos danos em função de vazamentos acidentais, em decorrência da operação de um processo de Refino de Petróleo.

\section{REFERENCIAL TEÓRICO}

Esta seção se subdivide em acidentes de trabalho, refino de petróleo, acidentes decorrentes de fissuras e rupturas em tubulações e consequências consideradas.

\section{ACIDENTES DE TRABALHO}

A definição legal de acidente de trabalho foi estabelecida pela Lei № 6.367, de 19 de outubro de 1976, artigo 2ㅇ e Decreto 79.037, de 24 de dezembro de 1976, artigo 2‥ Segundo esta legislação, o acidente de trabalho define-se como:

Aquele que ocorre pelo exercício do trabalho a serviço da empresa, ou ainda pelo exercício do trabalho de segurados especiais, provocando lesão corporal ou perturbação funcional, permanente ou temporária, que causa a morte, a perda ou a redução da capacidade para o trabalho (LEI 6.367, 1976).

Os índices de acidentes de trabalho no Brasil ainda são bastante preocupantes, deixando vítimas, provocando sequelas graves aos trabalhadores, perdas materiais para as organizações, enormes encargos sociais à Nação e grandes sofrimentos as famílias das vítimas (DELA COLETA, 1991).

De acordo com Coelho e Malaquias (2010, p. 17), podem ser equiparados a acidentes de trabalho: os sofridos fora do local de trabalho, mas decorrentes da execução de ordem ou na realização de serviços; viagem a serviço da empresa, no percurso da residência para o local de trabalho e vice e versa; e os ocorridos no período de refeição ou descanso. 
Para Araújo (2004), existe um convencimento de alguns especialistas de que o acidente é resultado de inúmeros fatores que interagem entre si, ou seja, de que este evento não é provocado por uma única causa e sim consequência de vários motivos envolvendo os desvios organizacionais. Para este autor, estes desvios demonstram a ineficácia do sistema de gestão em implementar procedimentos capazes de evitar a materialização do acidente.

\section{REFINO DE PETRÓLEO}

O petróleo bruto é uma complexa mistura de hidrocarbonetos, que apresenta contaminações variadas de enxofre, nitrogênio, oxigênio e metais. A composição exata dessa mistura varia significativamente em função do seu reservatório de origem. O refino do petróleo consiste na série de beneficiamentos pelos quais passa o mineral bruto, para a obtenção desses derivados, estes sim, produtos de grande interesse comercial. Esses beneficiamentos englobam etapas físicas, e químicas de separação, que originam as grandes frações de destilação. Estas frações são então processadas através de uma outra série de etapas de separação e conversão que fornecem os derivados finais do petróleo. Refinar petróleo é, portanto, separar as frações desejadas, processá-las e lhes dar acabamento, de modo a se obterem produtos vendáveis (MARIANO,2005).

Segundo Mariano (2005), o principal objetivo dos processos de refinação é a obtenção da maior quantidade possível de derivados de alto valor comercial, ao menor custo operacional possível, com máxima qualidade, minimizando-se ao máximo a geração dos produtos de pequenos valores de mercado. De um modo geral, uma refinaria, ao ser planejada e construída, pode se destinar a dois objetivos básicos:

a) Produção de produtos energéticos (combustíveis e gases em geral);

b) Produção de produtos não-energéticos (parafinas, lubrificantes, etc.) e petroquímicos.

O primeiro objetivo constitui a maior parte dos casos, pois a demanda por combustíveis é deveras maior do que a demanda por outros produtos. Nesse caso, a produção destina-se à obtenção de GLP, gasolina, Diesel, querosene e óleo combustível, entre outros.

O segundo grupo, não tão expressivo, é constituído de um grupo minoritário, onde o principal objetivo é a maximização da produção de frações básicas lubrificantes, parafinas e matérias-primas para a indústria petroquímica. Estes produtos possuem valores agregados muito superior ao dos combustíveis, o que confere aos refinadores altas rentabilidades, embora os investimentos envolvidos sejam também muito mais altos do que os necessários para o caso anterior.

De acordo com a Petrobras (2016) a produção de derivados a partir do petróleo envolve, basicamente, três processos principais:

- Destilação - é o processo de separação dos derivados: o petróleo é aquecido em altas temperaturas até evaporar. Esse vapor volta ao estado líquido conforme resfria em diferentes níveis dentro da torre de destilação. Em cada nível há um recipiente que coleta um determinado subproduto do petróleo;

- Conversão - é o processo que transforma as partes mais pesadas e de menor valor do petróleo em moléculas menores, dando origem a derivados mais nobres. Isso aumenta o aproveitamento do petróleo; 
- Tratamentos - são os processos voltados para adequar os derivados à qualidade exigida pelo mercado. Em um desses processos, por exemplo, é feita a remoção do enxofre.

Segundo Tavares $(2005$, p.28), a definição ideal dos processos a serem utilizados e da forma de combiná-los em uma refinaria depende das características do óleo bruto disponível e da demanda esperada de derivados, havendo ainda um "trade-off" entre a escolha irreversível de processos que exigem menor volume inicial de capital e o uso de um tipo de petróleo de melhor qualidade (mais caro); ou processos que demandam maior volume inicial de capital, mas que utilizam óleos de qualidade inferior (mais baratos). Além disso, é preciso que determinada refinaria atenda à demanda de seu mercado, tanto qualitativa, quanto quantitativamente, e que opere de modo a processar a gama de tipos de petróleo que lhe servem de matéria-prima da forma mais econômica e racional possível.

Figura 1 - Processo simplificado de refino de petróleo

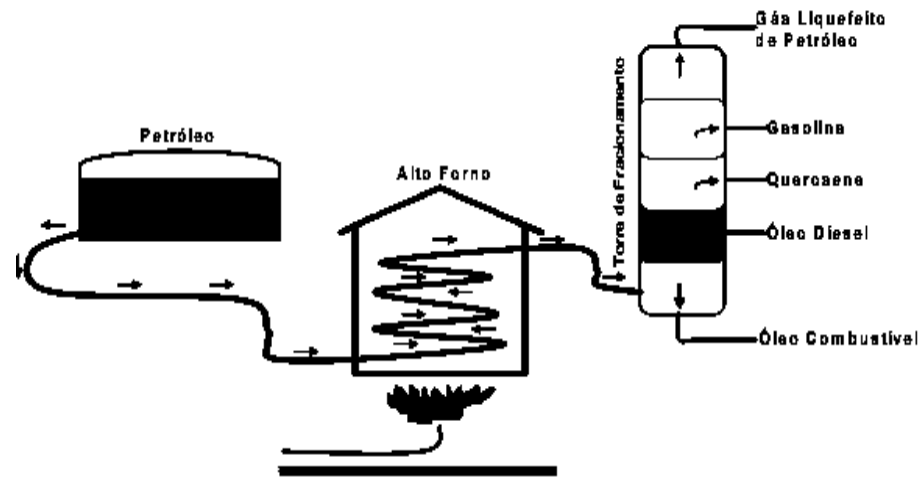

Fonte: Cardoso (2005, p. 70)

A Figura 1 demonstra como uma refinaria opera, de forma simplificada, para a obtenção dos derivados desejados. Trata-se do processo de separação denominado de destilação atmosférica. O petróleo é aquecido a altas temperaturas (em torno de $400^{\circ} \mathrm{C}$ ) e na torre de fracionamento, o petróleo bruto começa a desprender vapores. À medida que os vapores se elevam encontram os diversos "pratos" de condensação existente na torre. Nas partes mais altas ficam depositadas as frações de gás, nafta e gasolina; nas intermediárias, querosene e óleo diesel; e no fundo da torre, as frações de ponto de ebulição mais elevado, como o óleo combustível ou cru reduzido. (CARDOSO, 2005, p. 69-71).

\section{ACIDENTES DECORRENTES DE FISSURAS E RUPTURAS EM TUBULAÇÕES}

Este capítulo de subdive em fissuras e rupturas.

\section{Fissuras}

A fissura é uma das principais patologias que incide nas construções e, segundo Pfeffermann (1968) constitui-se num problema tão antigo quanto a própria existência da construção. De modo geral, a fissura pode ser entendida como a manifestação patológica resultante do alívio das tensões entre as partes 
de um mesmo elemento ou entre dois elementos em contato. A abertura ocasionada por ruptura de um material ou componente, com abertura inferior ou igual a $0,5 \mathrm{~mm}$. Fissura de componente estrutural: seccionamento na superfície ou em toda seção transversal de um componente, com abertura capilar, provocado por tensões normais ou tangenciais. As fissuras podem ser classificadas como ativas (variação da abertura em função de movimentações hidrotérmicas ou outras) ou passivas (abertura constante).

\section{Rupturas}

Os revestimentos devem apresentar capacidade de deformação, para se deformarem sem ruptura ou através de microfissuras que não comprometam a sua aderência, estanqueidade e durabilidade (SELMO, 1989).

A capacidade de absorver deformações permite ao revestimento deformarse, sem que ocorra a sua ruptura em qualquer ponto, ou deformar-se, com o surgimento de microfissuras que não prejudiquem o seu desempenho (SABBATINI; BARROS, 1990).

\section{CONSEQUÊNCIAS CONSIDERADAS}

Este capítulo se subdivide em jet fire, incêndio em poça, flash fire, explosão de nuvem e nuvem tóxica.

\section{Jet fire}

A maioria dos incêndios envolvendo gases liberados sob pressão está associada com altas pressões e são denominados incêndios de jato (i.e.jet fire), ou melhor, dado que um vazamento sob pressão seja deflagrado e sofra ignição entre 2 e 3 minutos após iniciado o vazamento, o resultado é um intenso jato de chamas. Em outras palavras, jet fire são chamas difusas e turbulentas resultante da combustão de líquidos ou gases liberados sob pressão de forma continua. Um jet fire é normalmente bastante destrutivo a qualquer estrutura nas suas proximidades, devido à radiação térmica e ao calor de convecção, além das extremidades da chama. A alta velocidade de escape dos gases e a adição de ar no jato tornam sua combustão mais eficiente do que a de um incêndio de poça (AICHE, 2005).

\section{Incêndio de poça}

Evento relacionado ao vazamento de um líquido que se acumula sobre uma superfície. Os vapores gerados sobre toda a área da poça estão formando uma mistura ideal de combustível e comburente bem próxima à superfície. Se houver uma fonte de ignição, toda a superfície será incendiada e o calor gerado pela combustão irá acelerar o processo de evaporação do líquido, aumentando o volume de vapor disponível. Embora o vazamento de líquidos seja de mais fácil deteç̧ão, pode haver dificuldades de eliminar o vazamento, seja pelo volume que está sendo derramado ou pela restrição de acesso (SOUZA,2013). 
A energia térmica proveniente de um vazamento de hidrocarbonetos depende de vários parâmetros, os quais incluem:

a) Composição do hidrocarboneto;

b) Tamanho, forma e duração do incêndio;

c) Distância entre o incêndio e o alvo;

d) Características do alvo.

Para a maioria dos combustíveis líquidos a taxa de transferência de calor por radiação e a velocidade de chama aumentam com o diâmetro da poça (AICHE, 1995).

\section{Flash fire}

Caracteriza-se pela ignição imediata de uma atmosfera inflamável oriunda do vazamento do produto. Este tipo de consequência é normalmente fatal, visto que por definição há um contato direto da chama com a vítima, e também há elevado grau de radiação térmica. Já as consequências para as instalações são reduzidas. O exemplo clássico de um flash fire seria a ignição de uma churrasqueira, após o encharcamento do carvão com álcool. Logo que espalhado, o álcool começa a evaporar-se formando uma nuvem inflamável. Com a presença de uma fonte de ignição (fósforo), a nuvem irá queimar-se total e instantaneamente, provocando a forte radiação térmica e a presença da chama em todo o seu volume (ZIMMERMANN,2009).

O flash fire é caracterizado pelo Limite Inferior de Inflamabilidade (L.E.L.). Uma definição clássica, obtém-se do manual do TNO (1999):

"um flash fire resulta da ignição de uma nuvem inflamável onde essencialmente não há aumento da taxa de combustão. Na verdade, a taxa de combustão num flash fire aumenta levemente comparada à fase laminar. Este aumento é principalmente devido às influências secundárias do vento e da rugosidade de superfície" (TNO, 1999).

O tamanho da nuvem inflamável determina a área possível de contato direto com a chama (AICHE, 1995).

\section{Explosão de nuvem}

A explosão é um processo onde ocorre uma rápida e violenta liberação de energia, associado a uma expansão de gases acarretando o aumento da pressão acima da pressão atmosférica (CETESB, 2011). Na indústria normalmente ocorre pela concentração de gases ou vapores inflamáveis em recintos fechados.

A explosão de uma nuvem de vapor é uma explosão resultante da ignição da nuvem, na qual as velocidades da chama aceleram até altas velocidades, sendo capaz de produzir uma sobrepressão significante (CCPS, 1994).

\section{Nuvem tóxica}

Nuvem tóxica consiste numa massa de vapor ou gás, causada por dispersão atmosférica de substância tóxica (DUARTE e DROGUETT, 2012).

Nuvens de gases tóxicos podem ser causadas por uma variedade de eventos, incluindo emissões acidentais em instalações industriais, acidentes durante o 
transporte de materiais perigosos e ataques envolvendo agentes de guerra química (BARBOSA et al., 2014).

\section{METODOLOGIA}

Obteve-se como fonte principal dos dados o referencial técnico conceitual relacionado aos Estudos de Impacto Ambiental -EIA e Relatório de Impactos de Meio Ambiente - RIMA da Refinaria Abreu e Lima, fornecido pela Petrobras em 22 de março de 2006, disponível para acesso público na Agência Estadual de Meio Ambiente e Recursos Hídricos - CPRH. Porém, por questões de confidencialidade, os dados de processos utilizados são fictícios.

\section{PREMISSAS}

Foram estimados os níveis de riscos provenientes apenas na unidade de Hidrotratamento de diesel considerada a unidade mais crítica devido às condições severas de temperatura, pressão e vazão, que tem o potencial de provocar maiores danos as pessoas e ao meio ambiente.

$\mathrm{Na}$ etapa de identificação dos perigos foi utilizada a análise preliminar dos perigos (APP), sendo realizada por trechos. Os trechos analisados possuem as mesmas características operacionais. Apenas os trechos mais críticos do processo foram analisados. A realização da análise foi realizada através do preenchimento de uma planilha para cada trecho considerado. Em outras palavras, foram identificadas e analisadas as causas dos vazamentos e de suas respectivas consequências. A avaliação preliminar da frequência de ocorrência do cenário, da severidade de suas consequências e do risco associado foram baseados na norma PETROBRAS N-2782.

Os cenários analisados foram pequeno vazamento e grande vazamento. Os critérios adotados para o pequeno e grande vazamento foram os estabelecidos pelo Banco Mundial, i.e., o pequeno vazamento e grande vazamento correspondem a $20 \%$ e $100 \%$ do diâmetro da tubulação, respectivamente, conforme. A integridade mecânica aumenta a confiabilidade das barreiras de proteção dos sistemas, através da redução da probabilidade de vazamentos, logo a frequência de eventos indesejáveis tais como incêndios, explosões e danos ambientais, será também reduzida.

O evento iniciador dos cenários identificados foram vazamentos de material inflamável. Os pequenos vazamentos ocorreram nas tubulações devido uma fissura provocado por corrosão. Os grandes vazamentos estão associados à ruptura da tubulação. $\mathrm{O}$ material liberado poderá está na fase de gás, liquida ou bifásica (líquido e gás).

O entendimento da evolução e consequências de um vazamento são imprescindíveis para a caracterização dos riscos (ou seja, quantificação da vulnerabilidade do receptor). Em nuvens flamáveis os gases/vapores são combustíveis. Se a nuvem possuir bolsões de concentração maior do que o menor limite de flamabilidade e se uma fonte de ignição estiver presente poderá ocorrer uma deflagração ou uma detonação. Se não ocorrer ignição haverá a formação de uma nuvem tóxica. A evolução de um vazamento acidental segue as 7 (sete) seguintes etapas: 
1. Inicialmente há um vazamento de uma substância perigosa, a qual poderá ser flamável, tóxica ou tóxica e flamável para o ambiente. Esse vazamento poderá ser na forma gasosa, líquida ou bifásica, conforme mencionado na descrição das formas de vazamentos;

2. Se a substância estiver na fase líquida, ocorrerá a evaporação do líquido;

3. Se a substância estiver na fase gasosa e sua concentração estiver dentro dos limites de flamabilidade há a possibilidade de uma ignição imediata;

4. Se a substância estiver na fase gasosa e for tóxica, ou flamável e não sofrer ignição imediata, essa poderá se dispersar no ambiente;

5. Se a substância for tóxica essa poderá causar fatalidades, danos a saúde ou ao ambiente se os limites de tolerância dos contaminantes estiverem acima dos limites aceitáveis;

6. Se houver ignição de uma nuvem flamável é provável ocorrer fatalidades ou danos à saúde decorrente do impacto térmico (i.e. incêndios) ou das ondas de choque (i.e. explosão);

7. Se a substância liberada estiver no estado líquido e sofre ignição um incêndio de poça será iniciado.

\section{SIMULAÇÃO}

O programa computacional ALOHA, desenvolvido pela Environmental Protection Agency - EPA e o SLAB recomendados para a caracterização dos incêndio e explosão na indústria de processamento foi utilizado na etapa de simulação dos alcances provocados pelos os efeitos físicos.

\section{Valores de referências}

\section{Limites dos efeitos físicos}

Os limites adotados foram a estabelecida pela Norma Técnica da CETESB P4. 261 (2003) e pelo TNO Purple Book (2005):

Radiação térmica:

$-3,0 \mathrm{~kW} / \mathrm{m}^{2}$;

$-12,5 \mathrm{~kW} / \mathrm{m}^{2}$;

$-37,5 \mathrm{~kW} / \mathrm{m}^{2}$.

Sobrepressão (utilizando o modelo de Multi-Energia da TNO):

- 0,7 psi;

$-1,5 \mathrm{psi} ;$

$-4,4$ psi.

\section{Características dos materiais de referência}

Dentre as hipóteses apresentadas para a quantificação do impacto dos incêndios e explosão às substâncias contempladas foram misturas de gases flamáveis sendo necessário selecionar uma substância de referência. Para uma substancia gasosa o material de referência selecionado foi o propano, para uma 
substancia bifásica o material foi $n$-hexano e para os líquidos o material de referência foi o n-decano, conforme apresentado na Tabela 1.

Tabela 1 - Materiais de referência

\begin{tabular}{ll} 
ELSTADO Fí́SICO & \multicolumn{1}{c}{ SUBSTÂNCIA PURA } \\
BIFÁSICO & $\mathrm{N}$ - decano \\
GÁs & $\mathrm{N}$ - hexano \\
\hline
\end{tabular}

Fonte: Autoria própria (2017).

\section{Tempo de vazamento}

O tempo de vazamento compreende o tempo para que seja detectada uma falha no sistema e o tempo para acionamento de fechamento das válvulas. É de extrema importância na simulação do vazamento, uma vez que irá definir a massa vazada e todos os desdobramentos possíveis.

TNO Purple Book (2005) estabelece valores padrões como diretrizes para o tempo de detecção do vazamento mais o tempo de operação do sistema de bloqueio, o que determina o tempo total de vazamento. Foi considerado apenas um sistema de bloqueio manual, no qual a detecção resulta num sinal numa sala de controle, onde um operador valida o sinal, vai para o local das válvulas de bloqueio e fecha-as manualmente, o tempo de vazamento são trinta minutos.

\section{Comprimento das linhas}

Considera-se para todas as tubulações, o valor hipotético de 2000 vezes o tamanho do diâmetro da tubulação, devido à falta de dados para tal.

\section{ANÁLISE PRELIMINAR DE RISCO (APR)}

Através desta análise tornou-se possível a realização da classificação qualitativa dos trechos analisados, que foram classificados de acordo como grau de frequência e de severidade. Na APR são levantadas as causas que podem promover a ocorrências de eventos e as suas respectivas consequências, sendo, então, feita uma avaliação qualitativa da frequência de ocorrência de cenários de acidentes, da severidade das consequências e do risco associado (AICHE, 1995).

A classificação quanto ao grau de frequência é obtida de forma global, como mostra a Figura 2.

Figura 2 - Categoria de frequência 


\begin{tabular}{|c|l|}
\hline Categoria & \multicolumn{1}{|c|}{ Descrição } \\
\hline $\begin{array}{c}\text { Extremamente Remota } \\
\text { B } \\
\text { Remota }\end{array}$ & $\begin{array}{l}\text { Conceitualmente possivel, mas extremamente improvável na vida útil da } \\
\text { instalação. Sem referências históricas. }\end{array}$ \\
\hline $\begin{array}{c}\text { Cão esperado ocorrer durante a vida útil da instalação, apesar de haver } \\
\text { referências históricas. }\end{array}$ \\
\hline $\begin{array}{c}\text { Pouco Provável } \\
\text { Provável }\end{array}$ & Possivel de ocorrer até uma vez durante a vida útil da instalação. \\
\hline $\begin{array}{c}\text { E } \\
\text { Freqüente }\end{array}$ & Esperado ocorrer mais de uma vez durante a vida útil da instalação. \\
\hline
\end{tabular}

Fonte: EIA/RIMA, (2006).

É possível observar na Figura 3, a classificação quanto ao grau de severidade, que é obtida de forma global.

Figura 3 - Categoria de severidade

\begin{tabular}{|c|l|}
\hline Categoria & Descrição \\
\hline $\begin{array}{c}\text { I } \\
\text { Desprezivel }\end{array}$ & Sem lesões, ou no máximo casos de primeiros socorros, sem afastamento. \\
\hline $\begin{array}{c}\text { II } \\
\text { Marginal }\end{array}$ & Lesões leves em empregados e terceiros. Ausência de lesões extramuros. \\
\hline $\begin{array}{c}\text { III } \\
\text { Crítica }\end{array}$ & $\begin{array}{l}\text { Lesões de gravidade moderada em pessoas intramuros. Lesões leves em pessoas } \\
\text { extramuros. }\end{array}$ \\
\hline IV & Provoca morte ou lesões graves em 1 ou mais pessoas intra ou extramuros. \\
\hline Catastrófica
\end{tabular}

Fonte: EIA/RIMA, (2006).

A Figura 4 apresenta a classificação quanto a frequência e a severidade. A partir dela, torna-se possível classificar o cenário de acordo com o grau de risco, que pode ser qualificado como Tolerável, Moderado ou Não Tolerável.

Figura 4 - Categoria de risco

\begin{tabular}{|c|c|c|c|c|c|c|}
\hline & \multicolumn{5}{|c|}{ Categorias de frequência } \\
\hline & & A & B & C & D & E \\
\hline \multirow{4}{*}{ 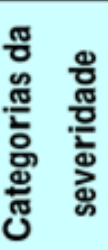 } & IV & $\mathrm{M}$ & M & NT & NT & NT \\
\hline & III & $\mathrm{T}$ & M & M & NT & NT \\
\hline & II & $\mathrm{T}$ & $\mathrm{T}$ & M & M & $\mathrm{M}$ \\
\hline & I & $\mathrm{T}$ & $\mathrm{T}$ & $\mathrm{T}$ & $\mathrm{T}$ & $\mathrm{M}$ \\
\hline
\end{tabular}

Fonte: EIA/RIMA, (2006). 


\section{RESULTADOS E DISCUSSÕES}

\section{ANÁLISE QUANTITATIVA DE RISCOS}

A análise Qualitativa foi realizada através do software ALOHA, ferramenta computacional que possibilita a obtenção do alcance dos efeitos físicos simulados a partir da temperatura e pressão do qual os três trechos em questão estão submetidos. A análise representada na Figura 5, foi feita com base no alcance classificado em três instâncias: dano alto (vermelho), dano médio (laranja) e dano baixo (amarelo). Vale salientar que, a categoria de intensidade do dano é representada em metros $(\mathrm{m})$.

Figura 5 - Possíveis efeitos: trecho 20

\begin{tabular}{|c|c|c|c|c|c|}
\hline \multicolumn{6}{|c|}{ 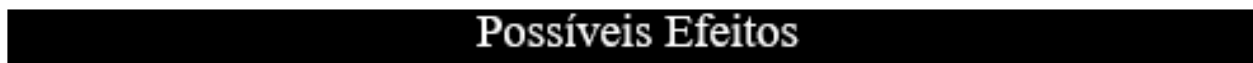 } \\
\hline \multicolumn{3}{|c|}{ Unidade: Hidrotratamento de Diesel } & \multicolumn{3}{|c|}{ Analistas: autores (2016) } \\
\hline \multirow{2}{*}{$\begin{array}{l}\text { Trecho: } 20 \\
\text { Temperatura: } 335.9 \\
{ }^{\circ} \mathrm{C}\end{array}$} & \begin{tabular}{|l} 
Diâmetro da \\
tubulação: 8 in
\end{tabular} & \multicolumn{3}{|c|}{ Tipo de fluido: Gás e liquido } & Revisão:1 \\
\hline & Pressão: $122.65 \mathrm{~atm}$ & \multicolumn{4}{|c|}{ Químicos: Hidrogênio $\left(\mathrm{H}_{2}\right)$} \\
\hline \multirow[t]{2}{*}{ Causas Prováveis } & Efeitos Possíveis & \multicolumn{3}{|c|}{ Categoria de intensidade do dano } & Cenário \\
\hline & & Amarelo & Laranja & Vermelho & \\
\hline \multirow{4}{*}{$\begin{array}{c}\text { Pequena liberação } \\
\text { de petróleo: } \\
\text { Fissura em } \\
\text { tubulação em } \\
\text { função da } \\
\text { corrosão }\end{array}$} & Flash Fire & 61 & 0 & 25 & 1 \\
\hline & Jet Fire & 14 & 0 & 0 & 2 \\
\hline & Explosão & 39 & 22 & 19 & 3 \\
\hline & Nuvem Tóxica & 0 & 0 & 0 & 4 \\
\hline \multirow{3}{*}{$\begin{array}{c}\text { Grande liberação } \\
\text { de petróleo: } \\
\text { Ruptura em } \\
\text { tubulação em } \\
\text { função da } \\
\text { corrosão }\end{array}$} & Flash Fire & 61 & 0 & 25 & 5 \\
\hline & Explosão & 39 & 22 & 19 & 6 \\
\hline & Nuvem Tóxica & 0 & 0 & 0 & 7 \\
\hline
\end{tabular}

Fonte: Autoria própria (2017)

As hipóteses de acidentes do trecho 20, representadas na Figura 5, simulam sete cenários oriundos de dois tipos de causas possíveis: Uma pequena liberação de petróleo (fissura) e uma grande liberação de petróleo (ruptura). Decorrente da fissura é possível que ocorram quatro cenários: o flash fire, podendo este ocasionar danos altos e médios, o jet fire, apenas com danos baixos e uma explosão, podendo esta ocasionar os três tipos de danos possíveis. Já em decorrência de uma ruptura, é possível a ocorrência de três cenários: fash fire, com danos altos e/ou baixos e explosão, podendo estar em todos os níveis de danos. Contudo, devido à baixa concentração de gás que foi formado sob 
condições de temperatura e pressão deste cenário, tornasse impossível a formação de uma nuvem tóxica, e desta forma o alcance dos efeitos físicos em decorrência do vazamento é igual a zero.

Figura 6 - Possíveis efeitos: trecho 31

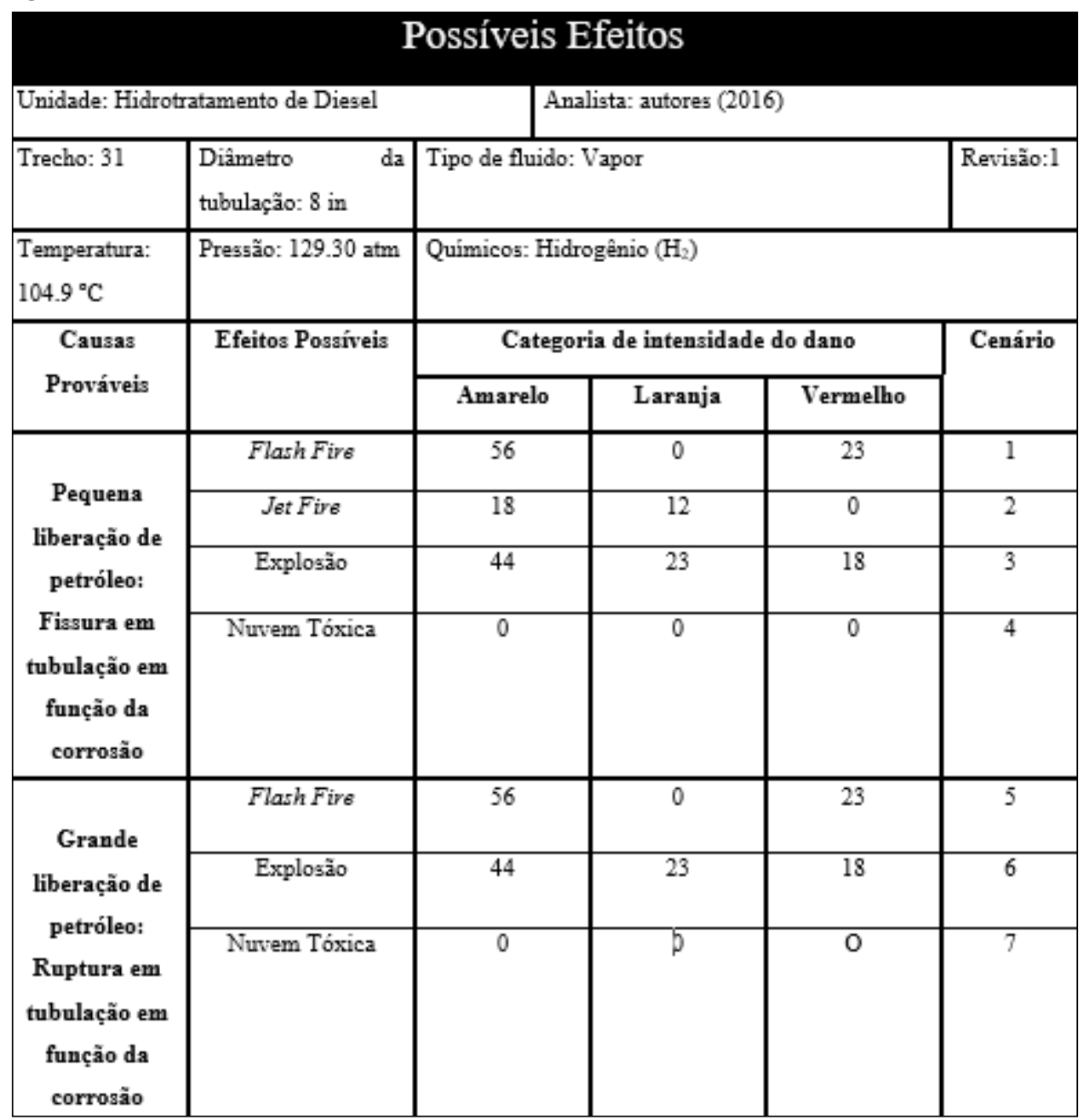

Fonte: Autoria própria (2017)

As hipóteses de acidentes do trecho 31, representadas na Figura 6, simulam sete cenários oriundos de dois tipos de causas possíveis: Uma pequena liberação de petróleo (fissura) e uma grande liberação de petróleo (ruptura). Decorrente da fissura é possível que ocorram quatro cenários: o flash fire, podendo este ocasionar danos altos e médios, o jet fire, com danos médios e baixos e uma explosão, podendo esta ocasionar os três tipos de danos possíveis. Já em decorrência de uma ruptura, é possível a ocorrência de três cenários: fash fire, com danos altos e/ou baixos e explosão, podendo estar em todos os níveis de danos. Contudo, devido à baixa concentração de gás que foi formado sob condições de temperatura e pressão deste cenário, tornasse impossível a formação de uma nuvem tóxica, e desta forma o alcance dos efeitos físicos em decorrência do vazamento é igual a zero. Vale salientar que, todas as distâncias da categoria de intensidade do dano foram expressas em metros $(m)$.

A Figura 7 apresenta os possíveis efeitos para o trecho de número 9. 
Figura 7 - Possíveis efeitos: trecho 9

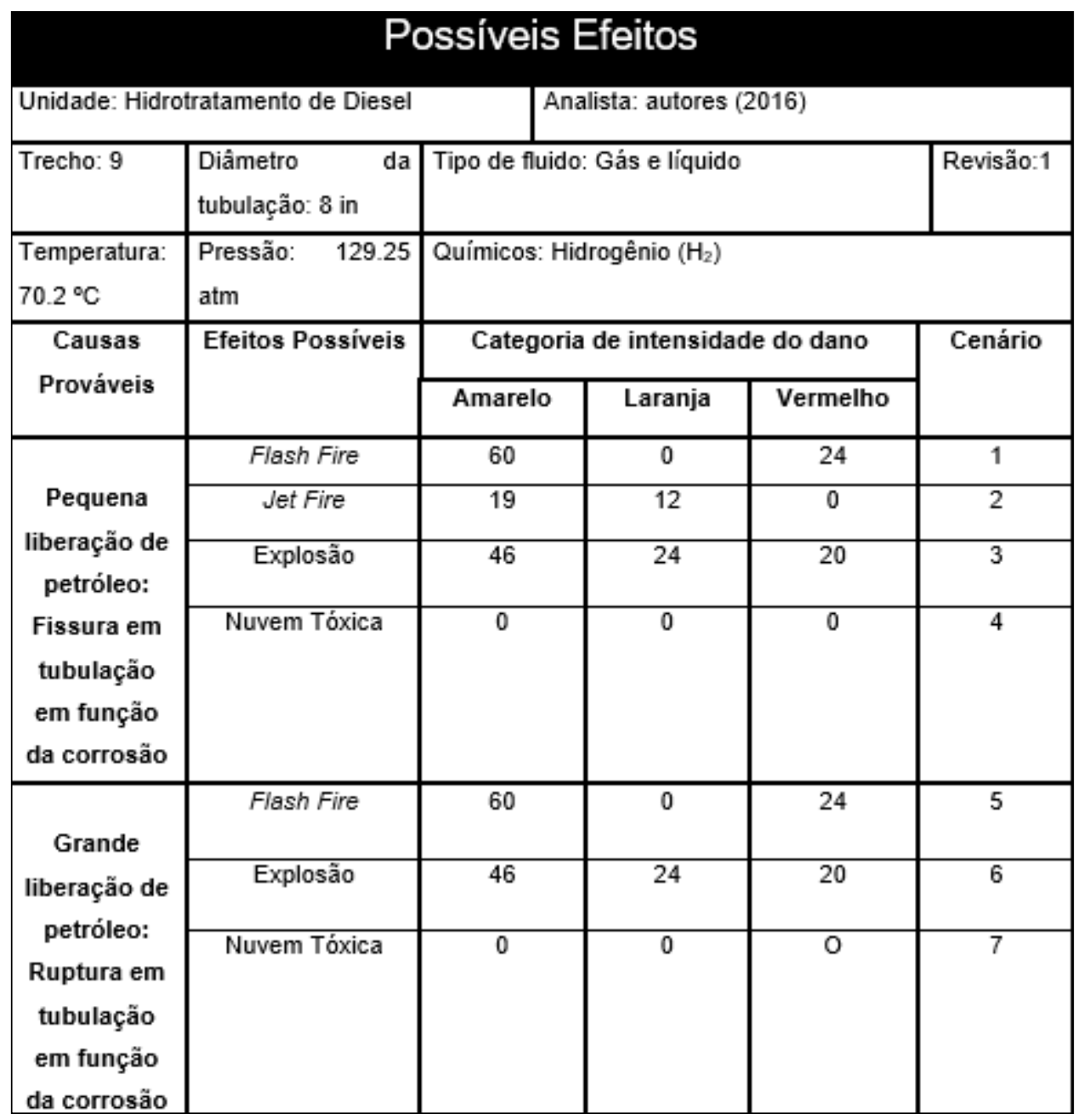

Fonte: Autoria própria (2017)

As hipóteses de acidentes do trecho 9, representadas na Figura 7, simulam sete cenários oriundos de dois tipos de causas possíveis: Uma pequena liberação de petróleo (fissura) e uma grande liberação de petróleo (ruptura). Decorrente da fissura é possível que ocorram quatro cenários: o flash fire, podendo este ocasionar danos altos e médios, o jet fire, com danos médios e baixos e uma explosão, podendo esta ocasionar os três tipos de danos possíveis. Já em decorrência de uma ruptura, é possível a ocorrência de três cenários: fash fire, com danos altos e/ou baixos e explosão, podendo estar em todos os níveis de danos. Contudo, devido à baixa concentração de gás que foi formado sob condições de temperatura e pressão deste cenário, tornasse impossível a formação de uma nuvem tóxica, e desta forma o alcance dos efeitos físicos em decorrência do vazamento é igual a zero. Vale salientar que, todas as distâncias da categoria de intensidade do dano foram expressas em metros $(m)$. 
Através dos resultados de alcances obtidos na etapa da análise quantitativa foi realizada uma APR - Análise Preliminar de Riscos, a fim de se obter classificações qualitativas dos trechos utilizados para estudo.

É possível observar na Tabela 2 a classificação para o trecho 20.

Tabela 2 - Avaliação da categoria de risco: trecho 20

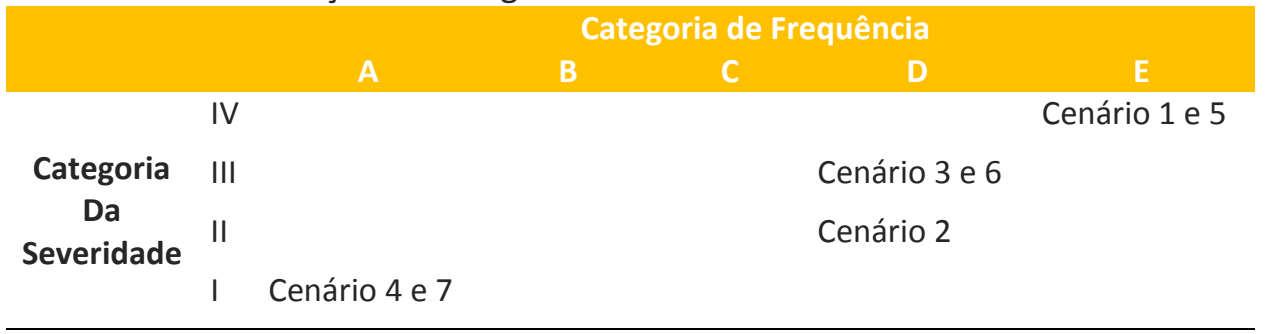

Fonte: Autoria própria (2017).

De acordo com a Tabela 2, e baseado nas definições das Figuras 3, 4 e 5, os cenários 1 e 5 são classificados com um grau de risco não tolerável dentro de um ambiente de trabalho, os cenários 3 e 6 também se encaixam neste grau de risco. Já o cenário 2 se classifica com um grau de risco moderado. Os cenários 4 e 5 são toleráveis com relação aos riscos.

A Tabela 3 apresenta a classificação para o trecho 31.

Tabela 3 - Avaliação da categoria de risco: trecho 31

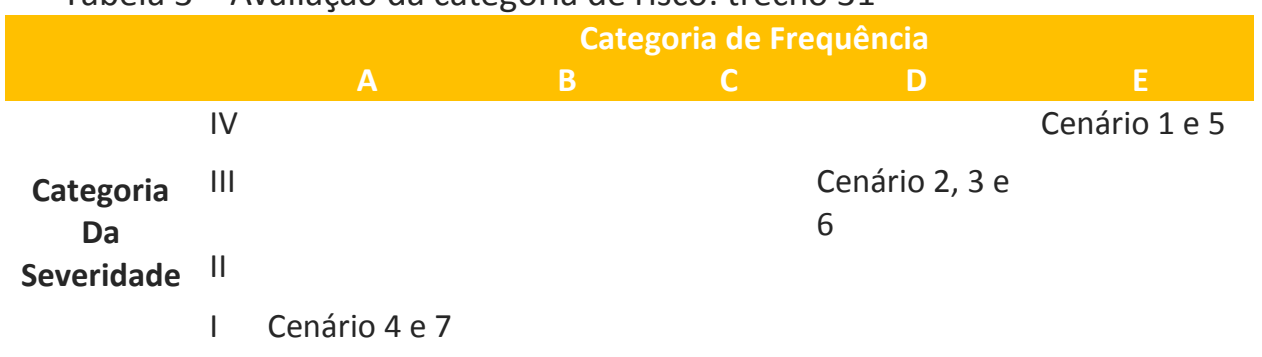

Fonte: Autoria própria (2017).

De acordo com a Tabela 3, e baseado nas definições das Figuras 3, 4 e 5, os cenários 1 e 5 são classificados com um grau de risco não tolerável dentro de um ambiente de trabalho, os cenários 2, 3 e 6 também se encaixam neste grau de risco. Já os cenários 4 e 5 possuem são toleráveis com relação aos riscos.

Vê-se na Tabela 4 a classificação para o trecho 9.

Tabela 4 - Avaliação da categoria de risco: trecho 9

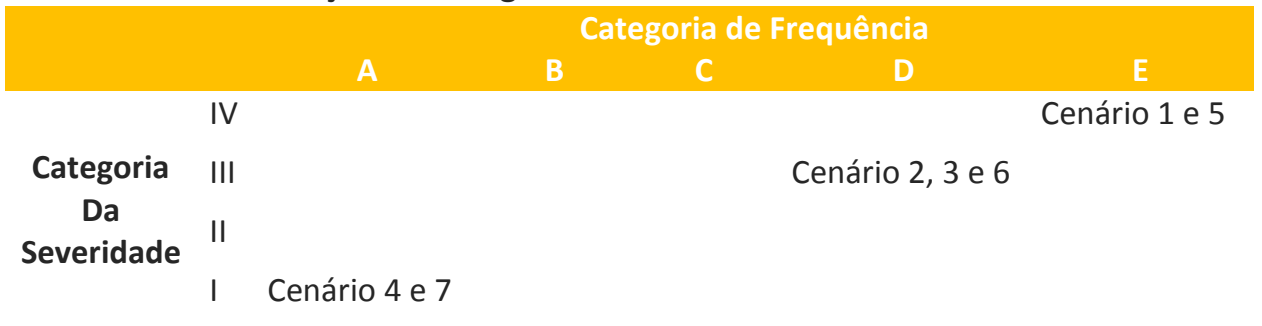

Fonte: Autoria própria (2017).

De acordo com a Tabela 4, e baseado nas definições das Figuras 3, 4 e 5, os cenários 1 e 5 são classificados com um grau de risco não tolerável dentro de um ambiente de trabalho, os cenários 2, 3 e 6 também se encaixam neste grau de risco. Já os cenários 4 e 5 possuem são toleráveis com relação aos riscos. 
Nota-se que os trechos possuem dados quantitativos relativos, porém por pequenas proporções o trecho 9 apresenta maiores índices quando levado em parâmetro as classificações qualitativas obtidas a partir dos alcances gerados por cada cenário, precisam-se este, assim, de uma certa prioridade, com relação a segurança do ambiente de trabalho.

\section{CONSIDERAÇÕES FINAIS}

Conclui-se que, diante do crescente desenvolvimento tecnológico nos processos industriais, torna-se indispensável o uso de softwares e programas que identifiquem os riscos e as zonas de ameaças existentes em cada ambiente químico de trabalho. Após a modelagem simulada proposta pelo software Aloha percebeu-se a existência de três trechos passíveis de acidentes, entretanto através do mesmo foi possível identificar que o trecho que precisava de mais atenção era o 9, pois em média de termos quantitativos e qualitativos apresentou os cenários mais críticos. Após a obtenção dos resultados foi possível uma classificação qualitativa dos dados através de uma APR - Análise Preliminar de Risco que detalha e qualifica cada um dos trechos.

Assim, o objetivo do trabalho foi concluído, pois foi possível identificar e quantificar os possíveis efeitos físicos dos danos em função de vazamentos acidentais, em decorrência da operação de um processo de Refino de Petróleo. Além disso, viu-se que a utilização de softwares na identificação de riscos além de facilitar o gerenciamento de todo o processo possibilita um controle maior nos departamentos que requerem mais atenção no que compete a segurança, diminuindo assim os custos e investimentos em segurança tornando a empresa apta e segura na realização de seus processos. 


\title{
Quantitative and Qualitative Analysis of the Risks of a Petroleum Refinery
}

\begin{abstract}
The growing technological development of industrial processes has directly impacted the occurrence of undesirable events such as work and environmental accidents, which in turn are vital parts in what concerns the management of information related to the area of finance and investment in insurance. In this scenario, we sought greater dedication on the part of government, businessmen, society and the technical-scientific community in understanding how to eliminate these risks when possible or to soften them in more complex cases. In this way, the present work had the objective of identifying and quantifying the possible physical effects of the damages, due to accidental leaks, resulting from the operation of a Petroleum Refining process. In order to obtain results with a minimum margin of error and a detailed control, we sought to use Aloha software, which allows the visualization of the inherent risks of specific activities to chemical working environments. In this way, a bibliographic research was necessary, combined with the knowledge acquired in the classroom to achieve this achievement. The work allowed to identify the estimates and the levels of the zones of threats of the existing dangers, being possible to quantify the possible physical effects of the damages in the refinery under study.
\end{abstract}

KEYWORDS: Accidents at work. Risk analysis. Refinery. 


\section{REFERÊNCIAS}

AICHE - American Institute of Chemical Engineers, Guidelines for hazard evaluation procedure. New York,1995.

ARAÚJO, G.M.; Legislação de Segurança e Saúde Ocupacional. 1ạ Edição; Rio de Janeiro, Gerenciamento Verde Editora e Livraria Virtual, 2006.

BARBOSA, Ilmar Victor M.; PINTO, José Carlos C.; NOGUEIRA, Evandro S. Simulações Multifásicas por Fluidodinâmica Computacional como Suporte ao Planejamento de Emergências com Agentes Químicos. Revista Virtual de Química, v. 6, n. 3, p. 795-814, 2014.

CARDOSO, Luiz Cláudio. Petróleo do poço ao posto. Rio de Janeiro: Qualitymark, 2005.

CETESB - Companhia de Tecnologia de Saneamento Ambiental do Estado de São Paulo. Manual P4.261 de orientação para elaboração de estudos de análise de riscos. São Paulo, Maio, 2003.

COELHO, Celso Pinto; MALAQUIAS, Kleber Caetano Antunes. Manual de segurança do trabalho e saúde ocupacional. Brasil: Eletrobrás, 2010.

COMPANHIA DE TECNOLOGIA AMBIENTAL DO ESTADO DE SÃO PAULO - CETESB. Risco de Acidente de Origem Tecnológica - Método para decisão e termos de referência. São Paulo: 2a Edição, Diário Oficial do Estado de São Paulo - Caderno Executivo I, v.124 (64) de 04/04/2014, Poder Executivo, Seção I, p. 83.

DELA COLETA, José Augusto. Acidentes de Trabalho. São Paulo: Atlas, 1991. DI LASCIO, C. H. R. A Psicologia no trabalho. Revista Contato - CRP 08, ano 23, no. 113, Curitiba, 2001, p.11.

DUARTE, Heitor de Oliveira; DROGUETT, Enrique Andrés López. Análise Quantitativa de Risco de uma unidade de recuperação de enxofre em uma refinaria de petróleo. Revista GEPROS, n. 2, p. 23, 2012

EIA/RIMA. Estudo e Relatório de Impacto Ambiental do Empreendimento "REFINARIA DO NORDESTE - RNEST". 2006. vol. 08.

FRANCO, L.S.; BARROS, M.M.S.B.; SABBATINI, F.H. Desenvolvimento de um método construtivo de alvenaria de vedação de blocos de concreto celular autoclavados. São Paulo, EPUSP-PCC, 1993. (Documento sobre a análise do sistema construtivo SICAL (MSPET) - EP/SICAL-1) 
MARIANO, Jacqueline Barbosa. Impactos ambientais do refino do petróleo. Rio de Janeiro: Interciência, 2005.

PETROBRÁS. Refino de Petróleo e Gás. 2015. Disponível em:

$<$ http://www.petrobras.com.br/pt/nossas-atividades/areas-de-atuacao/refino/>. Acesso em: 28 de set. 2016.

PFEFFERMANN, O. Les fissures dans les constructions conséquence de phénomenes physiques naturels. Annales de L'Institut Technique du Bâtiment et des Travaux Publics, v.21, n.250, p.1453-82, oct. 1968.

SELMO, S.M.S. Dosagem de argamassas de cimento portland e cal para revestimento externo de fachada de edifícios. São Paulo, 1989. 187p. Dissertação (Mestrado) - Escola Politécnica, Universidade de São Paulo.

SOUSA, Diohrge. Sistema de proteção contra incêndio e explosão para prevenção de acidentes industriais ampliados ou para redução de suas consequências. Porto Alegre: UFRGS, 2013.

TAVARES, Marina Elisabete Espinho. Análise do refino no Brasil: estado e perspectiva - uma análise "cross-section". Tese de Doutorado em Ciências em Planejamento Energético. Rio de Janeiro: COPPE/UFRJ, 2005.

TNO - The Netherlands Organization of Applied Scientific Research. Guidelines for Quantitative Risk Assesment - Guideline for Quantitative Risk Assesment "Purple Book". 3a ed. The Hague, 2005.

ZIMMERMANN, Adriana Thom. Análise de Riscos de um Vazamento de Gás Natural em um Gasoduto. Florianópolis: UFSC. 2009. 
Recebido: 24 jan. 2017

Aprovado: 22 set. 2017

DOI: 10.3895/gi.v13n2.5343

Como citar:

SOUZA, K. S. F. et al. Análise quantitativa e qualitativa dos riscos de uma refinaria de petróleo. R. Gest. Industr., Ponta Grossa, v. 13, n. 2, p. 107-125, jun./ago. 2017. Disponível em:

<https://periodicos.utfpr.edu.br/rgi >. Acesso em: XXX.

Correspondência:

Krisllen Samara Feitosa de Souza

Rua João da Cunha, 46, Monteiro, Paraíba, Brasil.

Direito autoral: Este artigo está licenciado sob os termos da Licença Creative Commons-Atribuição 4.0 Internacional.

(c) (1) 